\title{
Indole-3-carbinol: A Promising Hope for Cancer Therapy
}

\author{
Ahmed M. Kabel ${ }^{1,2, *}$, Eman A. Alharthi ${ }^{3}$, Rana K. Alshehri ${ }^{3}$, Afnan S. Alghamdi ${ }^{3}$ \\ ${ }^{1}$ Department of Clinical Pharmacy, College of Pharmacy, Taif University, Taif, KSA \\ ${ }^{2}$ Department of Pharmacology, Faculty of Medicine, Tanta University, Tanta, Egypt \\ ${ }^{3}$ Pharm D, College of Pharmacy, Taif University, Taif, KSA \\ *Corresponding author: drakabel@gmail.com
}

\begin{abstract}
Indole-3-carbinol (I3C) is a natural agent found in high amounts in cruciferous vegetables and is also available as dietary supplements. It is considered as a promising agent for the ongoing medical research due to its possible antioxidant, anti-inflammatory, anti-tumor, antiapoptotic and anti-atherogenic properties. Recent studies are directed towards assessment of the possible effects of $\mathrm{I} 3 \mathrm{C}$ on various body organs including the heart, liver, kidney and the endocrine system. This mini-review sheds light on the different properties of $\mathrm{I} 3 \mathrm{C}$ that make it a promising therapeutic agent for a wide variety of human diseases including cancer.
\end{abstract}

Keywords: cruciferous vegetables, indole-3-carbinol, natural agent, cancer

Cite This Article: Ahmed M. Kabel, Eman A. Alharthi, Rana K. Alshehri, and Afnan S. Alghamdi, "Indole-3-carbinol: A Promising Hope for Cancer Therapy." Journal of Cancer Research and Treatment, vol. 6, no. 1 (2018): 25-27. doi: 10.12691/jert-6-1-5.

\section{Introduction}

Chemotherapy side effects depend mainly on the drugs and the doses the patient receives. The use of the traditional anticancer agents such as doxorubicin, 5-fluorouracil, methotrexate and cisplation was faced by their dangerous adverse effects [1]. To decrease the dose and toxicity and increase the efficacy of chemotherapy regimens, various approaches were investigated. One of them was the search for natural agents with anticancer properties that can be used in combination with the traditional anticancer agents [2].

The anticancer properties of plants have been recognized for centuries. Isolation of podophyllotoxin and several other compounds from the common mayapple (Podophyllumpeltatum) ultimately led to the development of drugs used to treat testicular and small cell lung cancer [3]. Many studies have focused on the chemoprotective properties of plants such as the effect of Anacardiumocci dentale in hepatoma, Asparagus racemosa in human epidermoid carcinoma, Boswellia serrata in human epidermal carcinoma of the nasopharynx, Erthyrinasuberosa in sarcoma, Euphorbia hirta in Freund virus leukemia, Nigella sativa in lung carcinoma and Peaderiafoetida in human epidermoid carcinoma of the nasopharynx [1]. Their anticancer effects were attributed to antioxidant and anti-inflammatory properties together with affection of the cell cycle and induction of the expression of tumor suppressor genes such as p53. They have the advantage of being nearly devoid of adverse effect which gives them a crucial role in cancer therapy [4]. This article throws light on the different properties of indole-3-carbinol (I3C) that make it a promising therapeutic agent for a wide variety of human diseases.

\section{Derivatives of Cruciferous Vegetables and Their Effects}

Cruciferous vegetables had been of specific interest for years in cancer therapy due to their high content of glucosinolates, whose major breakdown products (isothiocyanates and indoles) have anticarcinogenic properties in vitro and in vivo [5]. Most of the isothiocyanates are metabolized in vivo through the mercapturic acid pathway. Indole compounds can react with ascorbic acid producing ascorbigen and, at the low $\mathrm{pH}$ of the stomach, a series of condensed products that may act as further bioactive compounds [6]. They were suggested to inhibit cancer cell growth by interfering with the production of proteins involved in abnormal cellular reproduction and by promoting the production of tumour suppressor proteins. Also, they were reported to affect cell proliferation, signal transduction and induce apoptosis in cancer cells by interfering with the production of compounds that cancer ordinarily produces to resist apoptosis [7].

Indole-3-carbinol (I3C) is produced by breakdown of the glucosinolate glucobrassicin, which can be found at high levels in cruciferous vegetables such as broccoli, cabbage, cauliflower, collard greens and kale. $\mathrm{I} 3 \mathrm{C}$ is also available in a dietary supplement [8]. I3C is the subject of ongoing biomedical research into its possible anticarcinogenic, antioxidant and cardioprotective effects. Research on I3C has been conducted primarily using laboratory animals and cultured cells. Recent studies found that there is an 
inverse association between cruciferous vegetable intake and the incidence of breast or prostate cancer [9].

\section{Pharmacokinetics of I3C}

After oral administration of $\mathrm{I3C}$, the compound is rapidly absorbed and had already reached an apparent peak concentration $15 \mathrm{~min}$ after dose [8]. However, plasma concentrations fall below the limit of detection within the first hour after dosing, indicating rapid distribution. $\mathrm{I} 3 \mathrm{C}$ is rapidly and extensively distributed into all tissues, with highest concentrations in the liver. I3C is rapidly metabolized to active metabolites including diindolymethane (DIM) and indole carbazole (ICZ) which are responsible for most of its beneficial effects [10].

\section{Actions and Medical Uses of I3C}

Recent studies have reported that $\mathrm{I} 3 \mathrm{C}$ and its metabolites have potent anticancer effects. The mechanisms of these effects were attributed to its ability to alter estrogen metabolism and other cellular effects. Estrogen receptors are present on the surface of every type of tissue in the bodies of the men and women and are associated with several hormone-dependent cancers [11].

I3C was reported to induce cell cycle arrest at the G1 phase in human reproductive cancer cells. This leads to prevention and treatment of cancer, as the G1 phase occurs early in the cell cycle, and, for most cells, is the major period of cell cycle during its lifespan. The G1 phase is marked by synthesis of various enzymes that are required in the next "S" phase, including those needed for DNA replication [10].

I3C can shift estrogen metabolism towards less estrogenic metabolites. Systemic lupus erythematosus is associated with estrogen. In a study using mice bred to develop lupus, the group fed with I3C diet lived longer and had fewer signs of disease [12]. Another study of lupus attributed the mechanism for this improvement to the sequential block of the development of B and T cells of these mice. This resulted in a fall in autoantibody production, thought to be a crucial component of lupus pathogenesis. In addition, $\mathrm{I} 3 \mathrm{C}$ of the disease prone mice led to a normalization of their $\mathrm{T}$ cell function [13].

Recent studies showed that I3C has beneficial effects on lipid metabolism that could be of great value for prevention of cardiotoxicity [14]. Moreover, other studies reported that $\mathrm{I} 3 \mathrm{C}$ might prevent cardiac remodeling via activation of AMP kinase enzyme leading to improvement of the myocardial functions and modulation of the expression of the genes that are responsible for the production of the hypertrophic and fibrotic markers with regeneration of the damaged myocardial tissues which significantly decreases the activity of the cardiac enzymes such as lactate dehydrogenase and creatine phosphokinase $[15,16]$.

\section{Adverse Effects of I3C}

I3C is likely safe for most people when used in the right amounts. Overuse of I3C supplements to prevent cancer may be unwise as the hormonal balance may be affected. Such caution is advised due to its effect on estrogen levels [17]. Also, it may promote development of liver cancer and enhance metastasis [18]. It was suggested that I3C enhances oxidative stress responses resulting in the induction of preneoplastic liver cell lesions in partially hepatectomized rats initiated with diethylnitrosamine [19].

\section{Conclusion}

I3C may represent a promising therapeutic agent for management of a wide variety of diseases including cancer, diabetes mellitus, endocrine disorders and cardiotoxicity. This may be attributed to its antioxidant, anti-inflammatory and anti-apoptotic properties together with its ability to restore the normal functions of the endocrine system of the human body. Further studies are needed to explore the molecular mechanisms that underlie these potential effects.

\section{References}

[1] Kabel AM, Abd Elmaaboud MA. Cancer: Role of Nutrition, Pathogenesis, Diagnosis and Management. World Journal of Nutrition and Health 2014; 2(4): 48-51.

[2] Al-Harthi SE, Alarabi OM, Ramadan WS, Alaama MN, Al-Kreathy HM, Damanhouri ZA, Khan LM, Osman AM. Amelioration of doxorubicin- induced cardiotoxicity by resveratrol. Mol Med Rep 2014; 10: 1455-60.

[3] Sultana S, Asif HM, Nazar HM, Akhtar N, Rehman JU, Rehman RU. Medicinal plants combating against cancer--a green anticancer approach. Asian Pac J Cancer Prev 2014; 15(11): 4385-94.

[4] Mondal S, Bandyopadhyay S, Ghosh MK, Mukhopadhyay S, Roy $\mathrm{S}$, Mandal C. Natural products: promising resources for cancer drug discovery. Anticancer Agents Med Chem 2012; 12(1): 49-75.

[5] Kabel AM, Al-Shehri AH, Al-Talhi RA, Abd Elmaaboud MA (2017). The promising effect of linagliptin and/or indole-3carbinol on experimentally-induced polycystic ovarian syndrome. Chemico-Biological Interactions 273: 190-199.

[6] Bosetti C, Filomeno M, Riso P, Polesel J, Levi F, Talamini R, Montella M, Negri E, Franceschi S, La Vecchia C. Cruciferous vegetables and cancer risk in a network of case-control studies. Ann Oncol 2012; 23 (8): 2198-203.

[7] $\mathrm{Hu} \mathrm{J}, \mathrm{Hu} \mathrm{Y,} \mathrm{Hu} \mathrm{Y,} \mathrm{Zheng} \mathrm{S.} \mathrm{Intake} \mathrm{of} \mathrm{cruciferous} \mathrm{vegetables} \mathrm{is}$ associated with reduced risk of ovarian cancer: a meta-analysis. Asia Pac J Clin Nutr 2015; 24(1): 101-9.

[8] Wang SQ, Cheng LS, Liu Y, Wang JY, Jiang W. Indole-3Carbinol (I3C) and its Major Derivatives: Their Pharmacokinetics and Important Roles in Hepatic Protection. Curr Drug Metab 2016, 17(4): 401-9.

[9] Higdon JV, Delage B, Williams DE, Dashwood RH. Cruciferous Vegetables and Human Cancer Risk: Epidemiologic Evidence and Mechanistic Basis. Pharmacol res 2007; 55(3): 224-236.

[10] Anderton MJ, Manson MM, Verschoyle RD, Gescher A, Lamb JH, Farmer PB, Steward WP, Williams ML. Pharmacokinetics and tissue disposition of indole-3-carbinol and its acid condensation products after oral administration to mice. Clin Cancer Res 2004; 10(15): 5233-41.

[11] Burns KA, Korach KS. Estrogen receptors and human disease: an update. Arch Toxicol 2012; 86(10): 1491-504.

[12] Auborn KJ1, Qi M, Yan XJ, Teichberg S, Chen D, Madaio MP, Chiorazzi N. Lifespan is prolonged in autoimmune-prone (NZB/NZW) F1 mice fed a diet supplemented with indole-3carbinol. J Nutr 2003; 133(11): 3610-13.

[13] Yan XJ, Qi M, Telusma G, Yancopoulos S, Madaio M, Satoh M, Reeves WH, Teichberg S, Kohn N, Auborn K, Chiorazzi N. Indole-3-carbinol improves survival in lupus-prone mice by inducing tandem B- and T-cell differentiation blockades. Clin Immunol 2009; 131(3): 481-94. 
[14] Chang HP, Wang ML, Hsu CY, Liu ME, Chan MH, Chen YH. Suppression of inflammation-associated factors by indole-3-carbinol in mice fed high-fat diets and in isolated, co-cultured macrophages and adipocytes. Int J Obes 2011; 35: 1530-38.

[15] Deng W, Wei L, Zong J, Bian Z, Zhou H, Zhang R, Tang Q Attenuation of cardiac remodeling by indole-3-carbinol in mice is associated with improved energy metabolism. Int J Cardiol 2014; 172: e531-e33.

[16] Rogan EG. The Natural Chemopreventive Compound Indole-3carbinol: State of the Science. In Vivo 2006; 20: 221-8.

[17] Hsu JC, Dev A, Wing A, Brew CT, Bjeldanes LF, Firestone GL. Indole-3-carbinol mediated cell cycle arrest of $\mathrm{LNCaP}$ human prostate cancer cells requires the induced production of activated p53 tumor suppressor protein. Biochem Pharmacol 2006; 72(12): 1714-23.

[18] Segawa R, Hayashi H, Morita R, Ogawa T, Takimoto N, Hara S, et al. Modifying effects of liver tumor promotion in rats subjected to co-administration of indole-3-carbinol and phenobarbital. J Toxicol Sci 2014; 39(1): 129-40

[19] Shimamoto K, Dewa Y, Ishii Y, Kemmochi S, Taniai E, Hayashi $\mathrm{H}$, et al. Indole-3-carbinol enhances oxidative stress responses resulting in the induction of preneoplastic liver cell lesions in partially hepatectomized rats initiated with diethylnitrosamine. Toxicology 2011; 283(2-3): 109-17. 